\title{
Review Paper on Different Dual Band Printed Slot Antenna for 5G Wireless Communication
}

\author{
Vibha Raj Nag', Mrinal Sarvagya ${ }^{2}$ \\ ${ }^{1}$ Department of Electronics and Communication Engineering, Atria Institute of Technology, Bangalore, India \\ ${ }^{2}$ Department of Electronics and Communication Engineerin, School of ECE, Reva University, Bangalore, India
}

\begin{tabular}{l}
\hline \hline Article Info \\
\hline Article history: \\
Received May 11, 2018 \\
Revised Jul 20, 2018 \\
Accepted Aug 3, 2018 \\
\hline
\end{tabular}

\section{Keywords:}

$5 \mathrm{G}$ wireless communication Dual band printed slot antenna Next generation wireless

\begin{abstract}
With advancement in communication technology over the past decade, there is an increasing demand for miniaturization, cost effective, multiband and wideband antennas. Dual band printed slot antenna designs can support in meeting these requirements. Various techniques, different shapes and geometries have been introduced for size reduction of dual band printed slot antennas. This paper is on various techniques for designing dual band printed slot antenna exhibits details of different geometries developed to get multiband behavior of printed slot antenna. In this paper geometry of the antenna and variousparameters such as return loss plot, gain plot, radiation pattern plot and VSWR plot are discussed. In this paper the review on various techniques of compactness by geometry on different shapes of printed slot antenna for $5 \mathrm{G}$ next generation wireless (NGW) mobile application are presented.
\end{abstract}

Copyright () 2018 Institute of Advanced Engineering and Science. All rights reserved.

\section{Corresponding Author:}

Vibha Raj Nag,

Department of Electronics and Communication Engineering,

Atria Institute of Technology, Bangalore, India.

\section{INTRODUCTION}

The fourth generation wireless communication systems have been deployed or are soon to be deployed in many countries. However, with an explosion of wireless mobile devices and services, there are still some challenges that cannot be accommodated even by $4 \mathrm{G}$, such as the spectrum crisis and high-energy consumption [1]. Wireless system designers have been facing the continuously increasing demand for high data rates and mobility required by new wireless applications. To address the above challenges the research on fifth generation wireless systems (5G) that are expected to be deployed beyond 2020 [1]. To meet the requirements of $5 \mathrm{G}$ to enable higher capacity, higher rate, more connectivity, higher reliability, lower latency, larger versatility and applicationdomain specific topologies, new concepts and design approaches are in great need. Future fifth generation wireless communication networks $(5 \mathrm{G})$ will most likely use millimeter-wave frequencies. Some work done by the authors on designing $5 \mathrm{G}$ antennas/arrays have been recently released [2-4].

Future 5G wireless communication networks will most likely use millimeter-wave frequencies. In this paper, the design of a dual-band printed slot Antenna which utilizing a band rejection element for the 5G Wireless applications is reviewd and comparison of dual-band printed slot antenna for the Future 5G mobile communication networks is optimized.

\section{GEOMETRIES OF PRINTED SLOT ANTENNAS}

In this paper, we compared different antenna geometries, all are printed Slot antennas. First, we analyzed all these geometries and then we discuss about their results. 


\subsection{Dual Frequency Printed Slot Antenna 1}

The overall dimension of patch 1 is simulated on a W $x \mathrm{~L}=8 \times 7.5 \mathrm{~mm}^{2}$, Substrate RogersRT5880 of $0.127 \mathrm{~mm}$ thickness, dielectric constant $\in \mathrm{r}=2.2$ and loss tangent $\tan \delta=0.0009$ [5]. Shown in Figure 1 . The optimized parameters of dual-band $5 \mathrm{~g}$ antenna on dual frequency printed slot antenna 1 shown in Table 1.

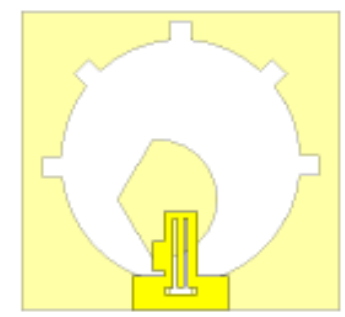

(a)

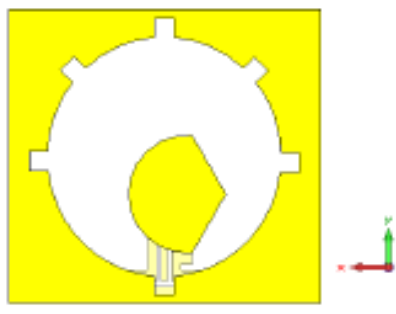

(b)

Figure 1. Geometrical Configuration of Dual-band 5G Antenna,

(a)Top View, and (b) Bottom View

Table 1. The Optimized Parameters of Dual-Band 5G Antenna (mm)

\begin{tabular}{cccccccccccc}
\hline $\mathrm{W}$ & $\mathrm{L}$ & $\mathrm{W}_{\mathrm{f}}$ & $\mathrm{L}_{\mathrm{f}}$ & $\mathrm{R}_{\mathrm{p}}$ & $\mathrm{R}_{\mathrm{s}}$ & $\mathrm{W}_{1}$ & $\mathrm{~L}_{1}$ & $\mathrm{~W}_{\text {stub }}$ & $\mathrm{L}_{\text {stub }}$ & $\mathrm{W}_{\mathrm{s}}$ & $\mathrm{L}_{\mathrm{s}}$ \\
\hline 8 & 7.5 & 2.42 & 0.8 & 1.5 & 3 & 1.58 & 1.66 & 0.85 & 0.29 & 0.5 & 0.28 \\
\hline
\end{tabular}

\subsection{Dual Frequency Printed Slot Antenna 2}

Figure 2 shows the geometry of basic design of broadband printed elliptical slot antenna. The prototype antenna is constructed on a 5 x $5 \mathrm{~mm} 2(\mathrm{~L} \mathrm{x} \mathrm{W})$ Rogers RT5880 of $0.127 \mathrm{~mm}$ thickness, dielectric constant $\mathrm{Er}=2.2$ and loss tangent $\tan \delta=0.0009$ [6]. The optimized parameters of dual-band $5 \mathrm{~g}$ antenna on dual frequency printed slot antenna 2 shown in Table 2 .

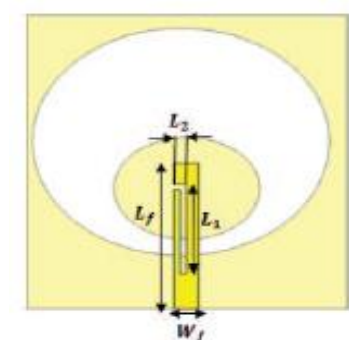

(a)

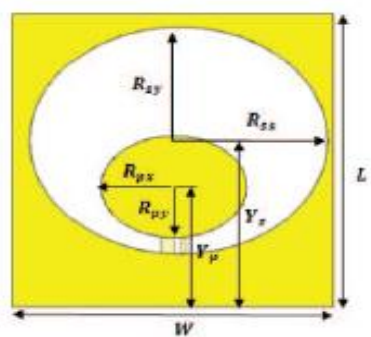

(b)

Figure 2. Geometrical Configuration of Dual-band 5G Antenna,

(a)Top View, and (b) Bottom View

Table 2. The Optimized Parameters of Dual-Band 5G Antenna (mm)

\begin{tabular}{llllllllllll}
\hline $\mathrm{W}$ & $\mathrm{L}$ & $\mathrm{W}_{\mathrm{f}}$ & $\mathrm{L}_{\mathrm{f}}$ & $\mathrm{L}_{1}$ & $\mathrm{~L}_{2}$ & $\mathrm{R}_{\mathrm{px}}$ & $\mathrm{R}_{\mathrm{py}}$ & $\mathrm{R}_{\mathrm{sx}}$ & $\mathrm{R}_{\mathrm{sy}}$ & $\mathrm{Y}_{\mathrm{s}}$ & $\mathrm{Y}_{\mathrm{p}}$ \\
\hline 5 & 5 & 0.39 & 2.53 & 1.5 & 0.095 & 1.12 & 0.87 & 2.32 & 1.95 & 2.83 & 2.03 \\
\hline
\end{tabular}

\subsection{Dual Frequency Printed Slot Antenna 3}

Figure 3 shows the geometry of dual band printed slot antenna design is of $10 \times 10 \mathrm{~mm} 2$ and is built on a $0.762 \mathrm{~mm}$-thick Neltec NH9320 substrate having the dielectric constant $\mathrm{Er}=3.2$ with loss tangent $\tan \delta=0.0024$. An offset sectorial disk radiating patch of radius $=1.5 \mathrm{~mm}$ is placed inside an elliptical shaped slot $A=4.150 \mathrm{~mm}, \mathrm{~B}=2.075 \mathrm{~mm}$ etched off the radiating plane. The center of the circular patch is on the same line of the substrate. The patch is excited using a $50-\Omega$ microstrip line with width $\mathrm{Wf}=1 \mathrm{~mm}$ and length, $\mathrm{Lf}=$ $4 \mathrm{~mm}$ [7]. The optimized parameters of dual-band $5 \mathrm{~g}$ antenna on dual frequency printed slot antenna 3 shown in Table 3. 


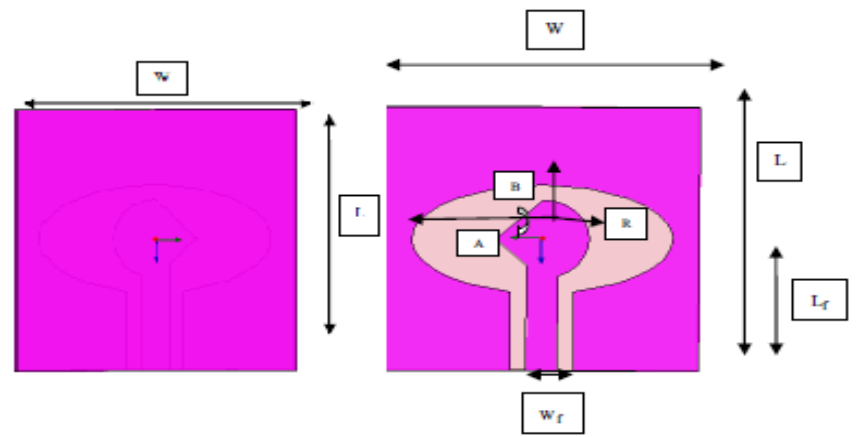

(a)

(b)

Figure 3.Geometry and Dimensions of Dual Band Printed Slot Antenna (a) Top View; (b) Bottom View

Table 3.The Optimized Parameters of Dual-Band 5G Antenna (mm)

\begin{tabular}{lllllll}
\hline $\mathrm{W}$ & $\mathrm{L}$ & $\mathrm{W}_{\mathrm{f}}$ & $\mathrm{L}_{\mathrm{f}}$ & $\mathrm{A}$ & $\mathrm{B}$ & $\mathrm{R}$ \\
\hline 10 & 10 & 1 & 4 & 4.150 & 2.075 & 1.5 \\
\hline
\end{tabular}

All the Simulation work is carried out using Ansoft HFSS and CST Microwave Studio simulation software.

\section{RESULTS ANALYSIS AND DISCUSSION}

In this paper we presented review work of three dual band printed slot antennas. Out of three Printed Slot antennas two antennas are on RogersRT5880 substrate of $0.127 \mathrm{~mm}$ thickness and one is on Neltec NH9320 substrate. The result analysis is done on the basis of Reflection coefficient graph, Bandwidth, Smith Chart and Gain vs Frequency curve of each antenna. We took each geometry one by one and analyzed it. The simulations of the proposed antenna are performed using HFSS [6] and Computer Simulation Technology (CST) Microwave Studio [6].

\subsection{Result Analysis of Printed Slot 1}

The proposed dual-band $5 \mathrm{G}$ antennas are illustrated in Figure 1. It is apparent that the proposed antenna can cover dual $5 \mathrm{G}$ bands of $28 / 38 \mathrm{GHz}$ for $|\mathrm{S} 11|$ less than $-10 \mathrm{~dB}$ with single notch band of $30-34 \mathrm{GHz}$ simulated with HFSS and CST Microwave Studio.

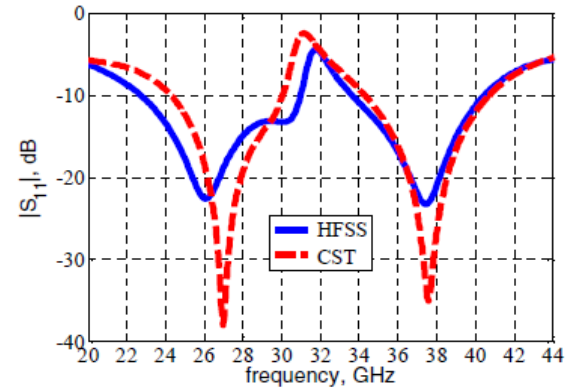

Figure 4. Reflection Coefficient $|\mathrm{S} 11|$ versus Frequency of Proposed Dualband 5G Antenna

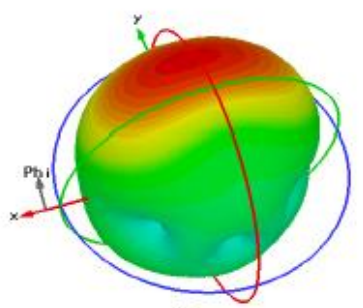

(a)

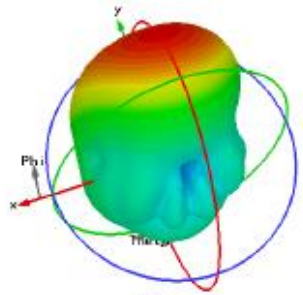

(b)
Figure 5. CST Simulated Radiation Patterns of Proposed Dual-band 5G Antenna at (a) $28 \mathrm{GHz}$, and (b) $38 \mathrm{GHz}$

Gain at both resonant frequencies is obtained from Gain curve which is shown in Figure 6. A stable gain with a value of $4.2 \mathrm{dBi}$ in the first band at $28 \mathrm{GHz}$ is observed and $6.9 \mathrm{dBi}$ in the second band at $38 \mathrm{GHz}$. 


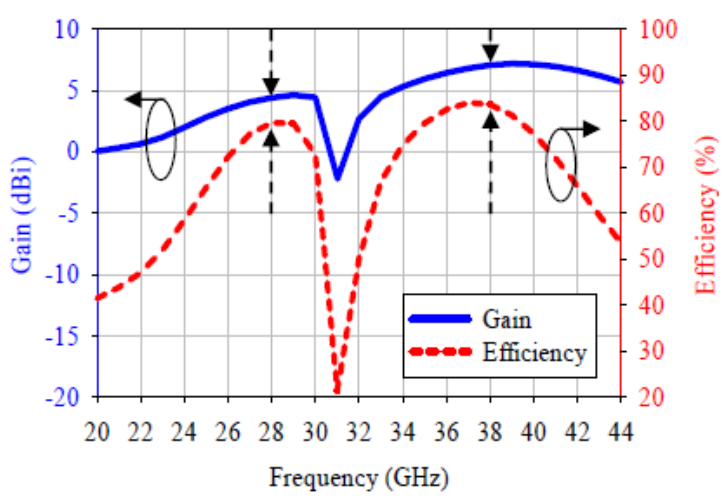

Figure 6. Maximum Realized Gain and Total Efficiency of Proposed Dualband 5G Antenna

\subsection{Result Analysis of Printed Slot 2}

The proposed dual-band $5 \mathrm{G}$ antennas are illustrated in Figure 2. It is clear that the proposed antenna can cover dual $5 \mathrm{G}$ bands of 28/38 GHz for S1 1 less than $-10 \mathrm{~dB}$ with single notch band of 30-34 GHz simulated with HFSS and CST Microwave Studio.

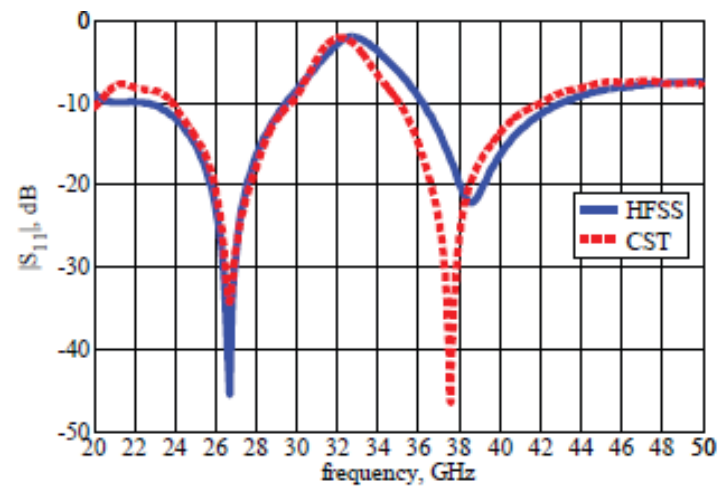

Figure 7. Simulated Reflection Coefficient $|\mathrm{S} 11|$ versus Frequency of Proposed Dual-band 5G Antenna

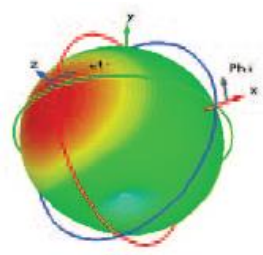

(a)
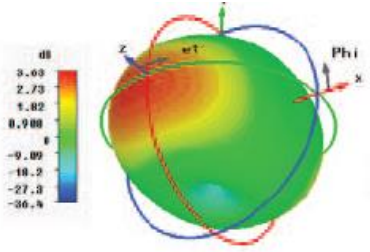

(b)



Figure 8. Simulated Radiation Patterns of Proposed Dual-Band 5G Antenna at Different Frequencies (a) $28 \mathrm{GHz}$, and (b) $38 \mathrm{GHz}$

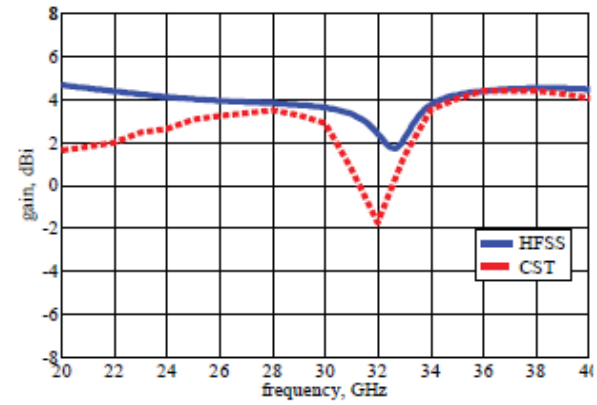

Figure 9. Simulated Maximum Realized Antenna Gain versus Frequency of Proposed Dual-Band 5G Antenna

It can be seen that the antenna gain is around 3.6-4.4 $\mathrm{dBi}$ over the operating band and the gain drops at notched frequency. 


\subsection{Result Analysis of Printed Slot 3}

The simulated results of the return loss /reflection coefficients $|\mathrm{S} 11|$ for the proposed dual band $5 \mathrm{G}$ antenna are shown in Figure 3. It shows that the proposed antenna has its $-10 \mathrm{~dB}$ band width for mmwave frequencies and cover dual $5 \mathrm{G}$ bands of $32 / 42 \mathrm{GHz}$ for $|\mathrm{S} 11|$ with the centre frequency at $31.5 \mathrm{and} 41.5 \mathrm{GHz}$ with the bandwidth of $1.5 \mathrm{GHz}$.

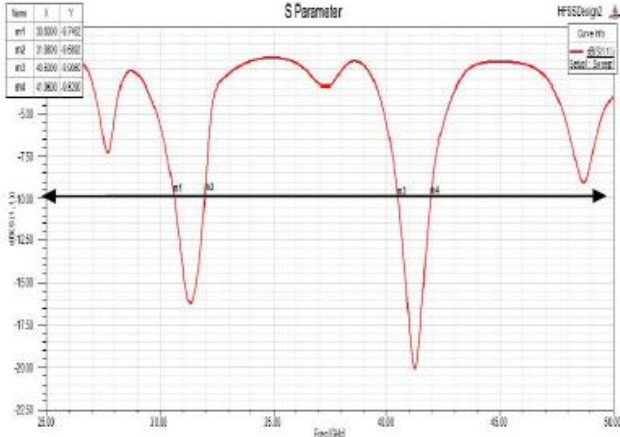

Figure 10. Reflection Coefficient $|\mathrm{S} 11|$ versus Frequency of Proposed Dual Band $5 \mathrm{G}$ Antenna


Figure 11. Simulated 3D Patteren

It shows that the proposed antenna has its $-10 \mathrm{~dB}$ band width for mmwave frequencies and cover dual $5 \mathrm{G}$ bands of $32 / 42 \mathrm{GHz}$ for $|\mathrm{S} 11|$ with the centre frequency at 31.5 and $41.5 \mathrm{GHz}$ with the bandwidth of 1.5 $\mathrm{GHz}$ each. The comparison of the antennas in figure shown in Table 4.

Table 4. Comparison of the Antennas in Figure

\begin{tabular}{|c|c|c|c|c|c|c|c|}
\hline DPSA & Slot Size & $\begin{array}{c}\text { Resonant } \\
\text { Freq }(\mathrm{GHz})\end{array}$ & $\begin{array}{c}\text { Bandwidth } \\
\text { GHz }\end{array}$ & $\begin{array}{c}\text { Current } \\
\text { Distribution }\end{array}$ & $\begin{array}{l}\text { Gain } \\
(\mathrm{dBi})\end{array}$ & Performance & Application \\
\hline \multirow[t]{2}{*}{ Antenna 1} & $8 \times 7.5 \mathrm{~mm}^{2}$ & $28 \mathrm{GHZ}$ & & & $4.2 \mathrm{dBi}$ & Dual band & $5 \mathrm{G}$ and $\mathrm{NGW}$ \\
\hline & & $38 \mathrm{GHz}$ & ------- & ------- & $6.9 \mathrm{dBi}$ & & \\
\hline \multirow[t]{2}{*}{ Antenna 2} & $5 \times 5 \mathrm{~mm}^{2}$ & $28 \mathrm{GHz}$ & & & $3.6 \mathrm{dBi}$ & Dual band & $5 \mathrm{G}$ and NGW \\
\hline & & $38 \mathrm{GHz}$ & ------- & ------- & $4.4 \mathrm{dBi}$ & & \\
\hline \multirow[t]{2}{*}{ Antenna 3} & $10 \times 10$ & $31.5 \mathrm{GHz}$ & $1.5 \mathrm{GHz}$ & & & Dual band & $5 \mathrm{G}$ and $\mathrm{NGW}$ \\
\hline & $\mathrm{mm}^{2}$ & $41.5 \mathrm{GHz}$ & $1.5 \mathrm{GHz}$ & ------ & ------- & & \\
\hline
\end{tabular}

\section{CONCLUSION AND FUTURE SCOPE}

In this paper, we examine three printed slot antennas. We start our work with reference slot 3, which have a frequency of 31.5 and $41.5 \mathrm{GHz}$ with dual band performance.The dual-band antennas slot 1 have gain up to $7 \mathrm{dBi}$ with sharp drop observed in the notched-frequency band near $31 \mathrm{GHz}$ and slot 2 at $33 \mathrm{GHz}$. Printed Slot antenna 2 provides almost omni-directional patterns, relatively flat gain, and high radiation efficiency through the frequency band excluding the rejected band. Slot 3 design illustrated a direction beam which makes it as a good candidate as for $5 \mathrm{G}$ and other high frequency applications. Further aim is to build an array with this element to improve the directivity for the application in the frequency range. Considering antenna parameters graph, we conclude that dual band Printed Slot antenna 3 is more appropriate in comparison to remaining antennas.

\section{REFERENCES}

[1] Z. Ying. Antennas in Cellular Phones for Mobile Communications, in Proceedings of the IEEE, Vol. 100, No. 7, pp. 2286- 2296, July 2012.

[2] Haraz, O.M.; Elboushi, A; Alshebeili, S.A; Sebak, A. Dense Dielectric Patch Array Antenna with Improved Radiation Characteristics Using EBG Ground Structure and Dielectric Superstrate for Future 5G Cellular Networks. Access, IEEE, vol.2, no., pp.909, 913, 2014.

[3] O. M. Haraz, A. Elboushi, A.-R. Sebak. New Dense Dielectric Patch Array Antenna for Future 5G Short-Range Communications. The $16^{\text {th }}$ international symposium on antenna technology and applied electromagnetics (ANTEM 2014), Victoria, Canada, July 13-17, 2014. 
[4] Broadband and Dual-Band Printed Slot Antennas for the Fifth Generation (5G) Mobile and Wireless Communications, 32nd National Radio Science Conference NRSC 2015, 6th of October city, Egypt.

[5] M. M. M. Ali, O. M. Haraz, S. Alshebeili, A.-R. Sebak. Design of Broadband and Dual-Band Printed Slot Antennas for the Fifth Generation (5G) Mobile and Wireless Communications, 32nd National Radio Science Conference NRSC 2015, 6th of October city, Egypt.

[6] Osama M. Haraz et al.. Design of a 28/38 GHz. Dual-Band Printed Slot Antenna for the Future $5 G$ Mobile Communication, IEEE International Symposium of Antennas and Propagation \& USNC/URSI National Radio Science Meeting, vol. 58, pp. 1532 - 1533, Oct 2015

[7] Nitin Kathuria, Shruti Vashisht, "Dual-band printed slot antenna for the $5 \mathrm{G}$ wireless communication network", IEEE,International Conference on Wireless Communications, Signal Processing and Networking (WiSPNET)PP: 1815 - 1817,Sep 2016

\section{BIOGRAPHIES OF AUTHORS}

\begin{tabular}{|c|c|}
\hline & $\begin{array}{l}\text { Ms. Vibha Rajnag is Pursu is pursuing Ph.D. degree in the field of Microstrip Patch Antenna from } \\
\text { VTU Bellagavi, Karnataka. Currently she is working as assistant professorin Atria Instirtute of } \\
\text { Technology in Department of Electronics and Communication. She has attended many } \\
\text { international and national conferences, seminars and workshops in the fields of antenna and digital } \\
\text { communication. She has more than Twenty research papers in national and international journals. } \\
\text { Her research interest includes She is Involved in teaching since } 2008 \text { and her major research } \\
\text { interest includes Antenna Designing, Microstrip patch antenna, Next Generation Wireless } \\
\text { Communication, 5G. }\end{array}$ \\
\hline & $\begin{array}{l}\text { Dr. Mrinal Sarvagya, Professor, School of Electronics and Communication Engineering } \\
\text { PhD degree in Wireless Communication from IIT Kharagpur, MTech degree in digital } \\
\text { Communication, (Course work from IIT kanpur) from DAVV Indore and B.E degree in } \\
\text { Electronics and communication Engineering " from Govt Engineering College Ujjain.". } \\
\text { She received the best thesis award from IIT Kharagpur in the year } 2009 \text { for her thesis titled "QoS } \\
\text { based packet scheduling and resource allocation schemes for WCDMA UMTS". She is the } \\
\text { member of Professional bodies WIE, IEEE. She has } 20 \text { years of teaching experience, } \\
\text { teaching various subjects like Wireless communication, Advanced Digital Communication, } \\
\text { Computer communication and networking, real time Operating Systems, Adhoc wireless } \\
\text { networks, Protocol Engineering. Her area of research is Wireless communication, channel } \\
\text { equalization in OFDM-IDMA / SCM receivers, Cognitive Radio networks. She has more } 60 \\
\text { publications in international journals and conferences. }\end{array}$ \\
\hline
\end{tabular}

